\title{
Influence of racial disparities on patient-reported satisfaction and short- and long-term perception of health status after elective lumbar spine surgery
}

\author{
Aladine A. Elsamadicy, BE, ${ }^{1}$ Hanna Kemeny, BS, ${ }^{1}$ Owoicho Adogwa, MD, MPH, ${ }^{2}$ \\ Eric W. Sankey, MD, ${ }^{1}$ C. Rory Goodwin, MD, PhD, ${ }^{1}$ Chester K. Yarbrough, MD, MPH, ${ }^{1}$ \\ Shivanand P. Lad, MD, PhD, ${ }^{1}$ Isaac 0. Karikari, MD, ${ }^{1}$ and Oren N. Gottfried, MD1
}

${ }^{1}$ Department of Neurosurgery, Duke University Medical Center, Durham, North Carolina; and ${ }^{2}$ Department of Neurosurgery, Rush University Medical Center, Chicago, Illinois

\begin{abstract}
OBJECTIVE In spine surgery, racial disparities have been shown to impact various aspects of surgical care. Previous studies have associated racial disparities with inferior surgical outcomes, including increased complication and 30-day readmission rates after spine surgery. Recently, patient-reported outcomes (PROs) and satisfaction measures have been proxies for overall quality of care and hospital reimbursements. However, the influence that racial disparities have on short- and long-term PROs and patient satisfaction after spine surgery is relatively unknown. The aim of this study was to investigate the impact of racial disparities on 3-and 12-month PROs and patient satisfaction after elective lumbar spine surgery.

METHODS This study was designed as a retrospective analysis of a prospectively maintained database. The medical records of adult (age $\geq 18$ years) patients who had undergone elective lumbar spine surgery for spondylolisthesis (grade 1), disc herniation, or stenosis at a major academic institution were included in this study. Patient demographics, comorbidities, postoperative complications, and 30-day readmission rates were collected. Patients had prospectively collected outcome and satisfaction measures. Patient-reported outcome instruments-Oswestry Disability Index (ODI), visual analog scale for back pain (VAS-BP), and VAS for leg pain (VAS-LP) - were completed before surgery and at 3 and 12 months after surgery, as were patient satisfaction measures.
\end{abstract}

RESULTS The authors identified 345 medical records for 53 (15.4\%) African American (AA) patients and 292 (84.6\%) white patients. Baseline patient demographics and comorbidities were similar between the two cohorts, with AA patients having a greater body mass index (33.1 $\left.\pm 6.6 \mathrm{vs} 30.2 \pm 6.4 \mathrm{~kg} / \mathrm{m}^{2}, p=0.005\right)$ and a higher prevalence of diabetes $(35.9 \%$ vs $16.1 \%, p=0.0008)$. Surgical indications, operative variables, and postoperative variables were similar between the cohorts. Baseline and follow-up PRO measures were worse in the AA cohort, with patients having a greater baseline ODI $(p<0.0001)$, VAS-BP score $(p=0.0002)$, and VAS-LP score $(p=0.0007)$. However, mean changes from baseline to 3- and 12-month PROs were similar between the cohorts for all measures except the 3-month VAS-BP score $(p=0.046)$. Patient-reported satisfaction measures at 3 and 12 months demonstrated a significantly lower proportion of AA patients stating that surgery met their expectations (3 months: $47.2 \%$ vs $65.5 \%, p=0.01 ; 12$ months: $35.7 \%$ vs $62.7 \%, p=0.007$ ).

CONCLUSIONS The study data suggest that there is a significant difference in the perception of health, pain, and disability between AA and white patients at baseline and short- and long-term follow-ups, which may influence overall patient satisfaction. Further research is necessary to identify patient-specific factors associated with racial disparities that may be influencing outcomes to adequately measure and assess overall PROs and satisfaction after elective lumbar spine surgery.

https://thejns.org/doi/abs/10.3171/2017.12.SPINE171079

KEYWORDS spinal surgery; race; satisfaction measures; patient-reported outcomes; lumbar

ABBREVIATIONS $A A=$ African American; $B M I=$ body mass index; $C A D=$ coronary artery disease; $D V T=$ deep vein thrombosis; $I Q R=$ interquartile range; $O D I=0$ swestry Disability Index; PE = pulmonary embolism; PRO = patient-reported outcome; UTI = urinary tract infection; VAS-BP = visual analog scale for back pain; VAS-LP = VAS for leg pain. SUBMITTED October 6, 2017. ACCEPTED December 18, 2017.

INCLUDE WHEN CITING Published online April 27, 2018; DOI: 10.3171/2017.12.SPINE171079. 
I $\mathrm{N}$ spine surgery, there has been an increased national emphasis on patient-reported outcomes (PROs) and satisfaction measures as proxies for quality of care and determinants of hospital reimbursements. The PROs afford health care providers insight into a patient's health status, functional disability, and quality of life. ${ }^{6}$ Though a subjective measure, preoperative expectations and postoperative satisfaction permeate the overall patient experience and have implications for follow-up PROs. ${ }^{31,32}$ In a prospective multicenter analysis of patients undergoing lumbar and cervical spine surgery, Soroceanu et al. demonstrated that the fulfillment of preoperative expectations was associated with higher postoperative satisfaction and patient-reported functional outcomes. ${ }^{30}$ Therefore, identifying factors that contribute to patient expectations and satisfaction are necessary to improve the overall perception of health after surgery.

Despite significant developments in the delivery of unbiased health care, racial disparities in surgical outcomes still exist across various specialties. . $^{5,12,14,25,26,29,33}$ Specifically in spine surgery, African American (AA) race has been associated with increased rates of postoperative complications, longer hospital stays, non-home discharges, 30day readmissions, and even death after surgery. 2,7,16,17,19,27 Moreover, other studies have associated racial disparities with surgical delay after diagnosis in symptomatic spine patients. ${ }^{10}$ Therefore, to identify areas for improvement, a consideration of race-dependent outcomes of spine surgery is essential. ${ }^{25}$ While there are several studies on outcome differences, there remains a paucity of data on the impact of racial disparities on short- and long-term PROs and satisfaction measures after spine surgery.

The aim of this study was to investigate the impact of racial disparities on 3- and 12-month PROs and satisfaction after elective lumbar spine surgery.

\section{Methods}

In this retrospective study of a prospectively maintained database, the medical records of all adult patients who had undergone elective lumbar spine surgery at a major academic institution were reviewed. Institutional review board approval was obtained prior to study initiation. All patients had been evaluated in the clinic of the institution's spine center.

Demographic variables evaluated included patient age, sex, and body mass index (BMI). Noted comorbidities included smoking status, depression, anxiety, diabetes, coronary artery disease (CAD), and osteoporosis. The presence of symptoms for longer than 3 months prior to surgery was also marked. Surgical indication included spondylolisthesis (grade 1), symptomatic disc herniation, or lumbar stenosis. Operative variables included approach type, laminectomy and/or laminotomy and median levels, arthrodesis and/or fusion and median levels fused, interbody grafts, instrumentation, and operative time. Noted postoperative complications included deep vein thrombosis (DVT), pulmonary embolism (PE), urinary tract infection (UTI), surgical site infection, hematoma, length of hospital stay, and 30-day readmission rate.

Patient-reported outcome metrics were prospectively
TABLE 1. Baseline demographics and comorbidities in patients who underwent elective lumbar spine surgery

\begin{tabular}{lccc}
\hline \multicolumn{1}{c}{ Variable } & AA Group & White Group & p Value \\
\hline No. of patients & 53 & 292 & \\
\hline Males (\%) & 43.4 & 57.2 & 0.06 \\
\hline Age at surgery in yrs & $54.5 \pm 13.6$ & $58.3 \pm 13.2$ & 0.06 \\
\hline Insurance status (\%) & & & \\
\hline Medicare & 43.4 & 35.6 & 0.28 \\
\hline Medicaid & 7.6 & 4.1 & 0.27 \\
\hline Private & 43.4 & 58.6 & $0.04^{*}$ \\
\hline High school diploma/GED or & 90.6 & 97.3 & $0.019^{*}$ \\
$\quad$ greater (\%) & & & \\
\hline On disability (\%) & 26.4 & 9.3 & $0.0004^{*}$ \\
\hline BMl in kg/m ${ }^{2}$ & $33.1 \pm 6.6$ & $30.2 \pm 6.4$ & $0.005^{*}$ \\
\hline Smokers (\%) & 24.5 & 15.4 & 0.10 \\
\hline Depression (\%) & 32.1 & 26.7 & 0.42 \\
\hline Anxiety (\%) & 18.9 & 17.5 & 0.81 \\
\hline Diabetes (\%) & 35.9 & 16.1 & $0.0008^{*}$ \\
\hline CAD (\%) & 0.0 & 11.34 & $0.01^{*}$ \\
\hline Osteoporosis (\%) & 1.9 & 4.8 & 0.34 \\
\hline Symptoms $>3$ mos (\%) & 92.5 & 95.4 & 0.36 \\
\hline GED Gen & \multicolumn{3}{c}{}
\end{tabular}

GED = General Equivalency Diploma.

Values expressed as the mean \pm standard deviation or as percentage, unless indicated otherwise.

* Statistically significant.

collected for both groups before surgery, as well as at 3 and 12 months after surgery. The PRO instruments included the Oswestry Disability Index (ODI) to measure functional status and the visual analog scale for back pain (VAS-BP) and the VAS for leg pain (VAS-LP) as metrics for back and leg pain. These questionnaires have been validated, widely used, and accepted in spine research. Satisfaction measures were also prospectively collected at 3- and 12-month postoperative follow-ups. Satisfaction measures were reported as follows: "surgery met my expectations," "I did not improve much but would undergo surgery for the same results," "I did improve but would not undergo surgery for the same results," and "I am the same or worse as compared to before surgery."

Parametric data were expressed as the mean \pm standard deviation and were compared via the Student t-test. Nonparametric data were expressed as the median (interquartile range [IQR]) and were compared using the MannWhitney U-test. Nominal data were compared with the chi-square test. All tests were two-sided and were statistically significant if the $p$ value was $<0.05$. Data preparation and statistical analysis were performed using JMP, version 12 (SAS Institute Inc.).

\section{Results}

\section{Demographics and Comorbidities}

A total of 345 patients comprising 53 AA patients and 292 white patients were included in this retrospective study. Baseline patient demographics were similar between the two cohorts except for a higher BMI in the AA 
TABLE 2. Operative and postoperative variables and readmission rates in patients who underwent elective lumbar spine surgery

\begin{tabular}{|c|c|c|c|}
\hline Variable & AA Group & White Group & $\begin{array}{c}p \\
\text { Value }\end{array}$ \\
\hline No. of patients & 53 & 292 & \\
\hline \multicolumn{4}{|l|}{ Surgical indication (\%) } \\
\hline $\begin{array}{l}\text { Lumbar spondylolisthesis } \\
\text { (grade 1) }\end{array}$ & 20.8 & 24.3 & 0.58 \\
\hline Lumbar disc herniation & 30.2 & 28.8 & 0.83 \\
\hline Lumbar stenosis & 49.1 & 46.6 & 0.74 \\
\hline \multicolumn{4}{|l|}{ Op variables } \\
\hline Pst approach (\%) & 96.2 & 95.2 & 0.75 \\
\hline Laminectomy/laminotomy (\%) & 96.2 & 88.5 & 0.09 \\
\hline Median levels [IQR] & $2[2-3]$ & $2[2-3]$ & 0.97 \\
\hline Arthrodesis/fusion (\%) & 26.4 & 33.6 & 0.31 \\
\hline Median levels fused [IQR] & $1[1-2]$ & $1[1-2]$ & 0.80 \\
\hline Interbody graft (\%) & 56.0 & 48.9 & 0.51 \\
\hline Instrumentation (\%) & 34.2 & 41.2 & 0.42 \\
\hline Op time in mins & $110.9 \pm 53.8$ & $119.8 \pm 62.1$ & 0.28 \\
\hline \multicolumn{4}{|l|}{ Postop variables } \\
\hline DVT (\%) & 0.0 & 0.0 & 1.00 \\
\hline PE (\%) & 0.0 & 0.0 & 1.00 \\
\hline UTI (\%) & 0.0 & 1.0 & 0.46 \\
\hline Surgical site infection (\%) & 1.9 & 0.7 & 0.39 \\
\hline Hematoma (\%) & 0.0 & 0.0 & 1.00 \\
\hline Length of hospital stay in days & $2.0 \pm 1.4$ & $1.5 \pm 1.2$ & $0.04^{*}$ \\
\hline 30 -day readmission rate (\%) & 5.7 & 3.1 & 0.35 \\
\hline
\end{tabular}

Pst $=$ posterior.

Values expressed as the mean \pm standard deviation, median [IQR], or percentage, unless indicated otherwise.

* Statistically significant.

cohort $\left(33.1 \pm 6.6\right.$ vs $30.2 \pm 6.4 \mathrm{~kg} / \mathrm{m}^{2}, \mathrm{p}=0.005$; Table 1). There were no significant differences in the proportion of patients with Medicare and Medicaid insurance; however, the white cohort had a greater proportion with private insurance than the AA cohort $(58.6 \%$ vs $43.4 \%$, $\mathrm{p}=0.04)$. Moreover, there was a significant difference in the proportion of patients with a high school diploma/General Equivalency Diploma or greater (AA: $90.6 \%$ vs white: $97.3 \%, \mathrm{p}=0.019$ ) and on disability (AA: $26.4 \%$ vs white: $9.3 \%, \mathrm{p}=0.0004)$. With respect to patient comorbidities, there was a significantly higher prevalence of diabetes in the AA cohort $(35.9 \%$ vs $16.1 \%, p=0.0008)$ and an increased prevalence of CAD among white patients $(0 \%$ vs $11.34 \%, p=0.01)$. No significant differences were observed between the cohorts with respect to other comorbidities including smoking status, depression, anxiety, or osteoporosis. Additionally, the percentage of patients with symptoms lasting longer than 3 months was not significantly different between the cohorts (AA: $92.5 \%$ vs white: $95.4 \%, \mathrm{p}=0.36)$.

\section{Intraoperative and Postoperative Variables}

Lumbar stenosis was the most common surgical indication (AA: $49.1 \%$ vs white: $46.6 \%, p=0.74$ ), followed by
TABLE 3. Baseline, 3-month, and 1-year PROs

\begin{tabular}{|c|c|c|c|}
\hline PRO & AA Group & White Group & p Value \\
\hline \multicolumn{4}{|l|}{ Baseline } \\
\hline ODI & $25.8 \pm 7.6$ & $20.8 \pm 7.7$ & $<0.0001^{*}$ \\
\hline VAS-BP & $7.8 \pm 2.3$ & $6.4 \pm 2.9$ & $0.0002^{*}$ \\
\hline VAS-LP & $7.7 \pm 2.8$ & $6.2 \pm 3.0$ & $0.0007^{*}$ \\
\hline \multicolumn{4}{|l|}{$3 \mathrm{mos}$} \\
\hline ODI & $19.6 \pm 10.7$ & $11.7 \pm 9.6$ & $<0.0001^{*}$ \\
\hline VAS-BP & $5.3 \pm 3.2$ & $3.0 \pm 3.0$ & $<0.0001^{*}$ \\
\hline VAS-LP & $4.2 \pm 3.9$ & $2.6 \pm 3.2$ & $0.004^{*}$ \\
\hline \multicolumn{4}{|l|}{$1 \mathrm{yr}$} \\
\hline ODI & $18.0 \pm 12.5$ & $11.4 \pm 9.7$ & $0.01^{*}$ \\
\hline VAS-BP & $4.8 \pm 3.9$ & $3.2 \pm 3.2$ & $0.047^{*}$ \\
\hline VAS-LP & $4.0 \pm 4.0$ & $2.9 \pm 3.3$ & 0.18 \\
\hline \multicolumn{4}{|c|}{$\Delta$ from baseline to 3 mos } \\
\hline ODI & $6.2 \pm 10.7$ & $9.0 \pm 9.0$ & 0.08 \\
\hline VAS-BP & $2.5 \pm 2.9$ & $3.4 \pm 3.3$ & $0.046^{*}$ \\
\hline VAS-LP & $3.4 \pm 4.8$ & $3.6 \pm 3.7$ & 0.82 \\
\hline \multicolumn{4}{|c|}{$\Delta$ from baseline to $1 \mathrm{yr}$} \\
\hline ODI & $7.5 \pm 9.3$ & $9.5 \pm 9.3$ & 0.30 \\
\hline VAS-BP & $2.5 \pm 3.5$ & $3.2 \pm 3.9$ & 0.32 \\
\hline VAS-LP & $3.8 \pm 4.7$ & $3.5 \pm 3.7$ & 0.75 \\
\hline
\end{tabular}

Values expressed as the mean \pm standard deviation, unless indicated otherwise.

* Statistically significant.

lumbar disc herniation (AA: $30.2 \%$ vs white: $28.8 \%$, p = 0.83 ) and grade 1 lumbar spondylolisthesis (AA: $20.8 \%$ vs white: $24.3 \%, p=0.58$; Table 2). The proportion of posterior approaches was similar for the two cohorts (AA: $96.2 \%$ vs white: $95.2 \%, \mathrm{p}=0.75)$. The proportion that underwent laminectomy/laminotomy was $96.2 \%$ in the AA patients and $88.5 \%$ in the white patients $(\mathrm{p}=0.09)$, with a similar number of median levels [IQR] treated (AA: 2 [2-3] vs white: 2 [2-3], $\mathrm{p}=0.97)$. The proportion that underwent arthrodesis/fusion was similar in the two groups (AA: $26.4 \%$ vs white: $33.6 \%, p=0.31$, with similar median levels fused $(1$ [1-2] vs 1 [1-2], respectively, $\mathrm{p}=0.80)$. The mean operative times for the AA and white cohorts were $110.9 \pm 53.8$ and $119 \pm 62.1$ minutes, respectively $(p=0.28)$.

The prevalence of postoperative complications was similar between the cohorts (AA vs white): DVT $(0.0 \%$ vs $0.0 \%)$, PE ( $0.0 \%$ vs $0.0 \%)$, UTI ( $0.0 \%$ vs $1.0 \%)$, surgical site infection $(1.9 \%$ vs $0.7 \%)$, hematoma $(0.0 \%$ vs $0.0 \%$; Table 2). African American patients had a significantly longer hospital stay than the white patients $(2.0 \pm 1.4$ days vs $1.5 \pm 1.2$ days, respectively, $\mathrm{p}=0.04$ ). There was no significant difference in the 30-day readmission rates between the two cohorts (AA: $5.7 \%$ vs white: $3.1 \%, \mathrm{p}=0.35$ ).

\section{Baseline, 3-Month, and 1-Year PRO Measures}

At baseline, there were significant differences between the AA and white cohorts in the ODI, VAS-BP, and VAS-LP scores (Table 3): ODI $25.8 \pm 7.6$ vs $20.8 \pm 7.7$, respectively, $\mathrm{p}<0.0001$; VAS-BP $7.8 \pm 2.3$ vs $6.4 \pm 2.9$, respectively, $\mathrm{p}<0.0002$; VAS-LP $7.7 \pm 2.8$ vs $6.2 \pm 3.0$, 
TABLE 4. Three-month and 1-year satisfaction measures

\begin{tabular}{|c|c|c|c|}
\hline \multirow[b]{2}{*}{ Satisfaction Measure } & \multicolumn{2}{|c|}{$\%$} & \multirow[b]{2}{*}{$\begin{array}{c}p \\
\text { Value }\end{array}$} \\
\hline & $\begin{array}{c}\text { AA } \\
\text { Group }\end{array}$ & $\begin{array}{l}\text { White } \\
\text { Group }\end{array}$ & \\
\hline \multicolumn{4}{|l|}{$3 \mathrm{mos}$} \\
\hline Surgery met my expectations & 47.2 & 65.5 & $0.01^{*}$ \\
\hline $\begin{array}{l}\text { I did not improve much but would un- } \\
\text { dergo surgery for the same results }\end{array}$ & 30.2 & 20.3 & 0.11 \\
\hline $\begin{array}{l}\text { I did improve but would not undergo } \\
\text { surgery for same results }\end{array}$ & 7.6 & 5.5 & 0.56 \\
\hline $\begin{array}{l}\text { I am the same or worse as compared } \\
\text { to before surgery }\end{array}$ & 15.1 & 8.6 & 0.14 \\
\hline \multicolumn{4}{|l|}{$1 \mathrm{yr}$} \\
\hline Surgery met my expectations & 35.7 & 62.7 & $0.007^{*}$ \\
\hline $\begin{array}{l}\text { I did not improve much but would un- } \\
\text { dergo surgery for the same results }\end{array}$ & 25.0 & 19.2 & 0.48 \\
\hline $\begin{array}{l}\text { I did improve but would not undergo } \\
\text { surgery for the same results }\end{array}$ & 17.9 & 9.0 & 0.15 \\
\hline $\begin{array}{l}\text { I am the same or worse as compared } \\
\text { to before surgery }\end{array}$ & 21.4 & 9.0 & $0.049^{*}$ \\
\hline
\end{tabular}

respectively, $\mathrm{p}<0.0007$. At 3 months after surgery, these differences remained significant and continued at the 1-year follow-up for ODI (AA: $18.0 \pm 12.5$ vs white: 11.4 $\pm 9.7, \mathrm{p}<0.01)$ and VAS-BP (AA: $4.8 \pm 3.9$ vs white: $3.2 \pm$ $3.2, \mathrm{p}<0.047$ ). Mean changes in PROs from baseline to 3 months and 1 year after surgery were similar between the cohorts except the 3-month VAS-BP score (AA: $2.5 \pm 2.9$ vs white: $3.4 \pm 3.3, \mathrm{p}=0.046$ ).

\section{Three-Month and 1-Year Satisfaction Measures}

At 3 months after surgery, a significantly lower proportion of AA patients responded that "surgery met my expectations" compared with white patients $(47.2 \%$ vs $65.5 \%$, respectively, $\mathrm{p}=0.01$; Table 4 ). Additionally, AA patients tended to respond that they "did improve but would not undergo surgery for same results" more often than the white patients ( $7.6 \%$ vs $5.5 \%$, respectively, $\mathrm{p}=0.56$ ).

At the 1-year follow-up, some differences in satisfaction measures continued between the cohorts, with a significantly lower proportion of AA patients reporting "surgery met my expectations" compared with a minimal decrease in the white patients reporting the same (35.7\% vs $62.7 \%$, respectively, $\mathrm{p}=0.007$; Table 4 ). Additionally, there was an increasing trend in the percentage of AA patients reporting that they "did improve but would not undergo surgery for the same results" (AA: $17.9 \%$ vs white: $9.0 \%$, $\mathrm{p}=0.15$ ).

\section{Discussion}

In this retrospective study of 345 patients who had undergone elective lumbar spine surgery, our results suggest that racial disparities may have an impact on short- and long-term PROs and patient satisfaction measures.

Race has been found to be a determinant in patient management and assessment, as well as in the preference to undergo spine surgery. In a retrospective study of 133 patients undergoing elective anterior cervical discectomy and fusion (ACDF), Elsamadicy et al. found that race was an independent predictor of the duration of preoperative pain and a delay in diagnosis and treatment. ${ }^{10}$ With regard to treatment decision-making, an analysis of 2323 patients with spinal disorders in the Spine Patient Outcomes Research Trial (SPORT) by Arega et al. revealed that AA patients were less likely to prefer surgical treatment than white patients. ${ }^{4}$ Similarly, in a retrospective study of 965,600 anterior cervical spine procedures, Alosh et al. showed that while rates of surgery increased by $289 \%$ in the United States, adjusted rates of surgery were lowest among minority populations. ${ }^{3}$ In addition to a decreased efficacy with surgical delays, there are implications for economic costs. In a retrospective cost-utility analysis of 169 patients who had undergone spine surgery for cervical or lumbar radicular pain, Räsänen et al. found a twofold increase in the associated cost per quality-adjusted life year gained in the delayed-surgery cohort versus the cohort with early surgical intervention. ${ }^{23}$ These studies indicate a need for further exploration of health care disparities and decision-making to provide better patient care to nonwhite populations.

Several studies have demonstrated inferior surgical outcomes in AA patients electing to undergo spine surgery. Lad et al. found that AA patients were significantly more likely than white patients to develop a postoperative complication and have a longer hospital stay after undergoing primary laminectomy or fusion for spinal stenosis. ${ }^{17}$ Analogously, Seicean et al. showed that, after undergoing elective spinal surgery, AA patients had a higher postoperative complication rate, longer hospital stay, and an increased demand for continuing care after discharge compared with those in white patients. ${ }^{27}$ Alosh and colleagues demonstrated a significantly higher in-hospital mortality rate in AA patients than in white patients. ${ }^{3}$ While several studies have demonstrated the implications of racial disparities on complication rates and health care resource utilization, there have been few studies identifying similar associations for 30-day readmissions after elective spinal surgery. In two single-institution studies of patients undergoing elective spinal surgery, Adogwa et al. and Martin et al. both reported an independent association between race and 30-day unplanned readmission. ${ }^{1,20}$ While there have been several postulations about racial differences in surgical outcomes, ${ }^{11,13,22}$ further understanding of the impact that racial disparities have on perioperative complications and outcomes is necessary to improve patient care.

Along with the complications and lower health outcomes, inferior baseline and postoperative PROs among AA patients undergoing spine surgery have been shown in previous studies. In a retrospective review of prospectively collected data on 2427 patients with spinal disorders from the SPORT, Schoenfeld et al. revealed that AA patients reported higher symptom severity, lower functionality, and greater pain at baseline than in the white cohort. ${ }^{24}$ Moreover, the authors found that in the 1593 patients who elected to undergo spine surgery, AA patients had worse body pain, physical function, and disability PROs compared with those in white patients up to the 4-year follow-up. ${ }^{24}$ 
Similarly, in analyzing prospectively collected data from the Quality Outcomes Database on 7618 patients following spinal surgery, McGirt et al. found that AA race was significantly associated with lower odds of having better disability scores, quality of life, and leg pain scores 1 year postoperatively. ${ }^{21}$ Additionally, in an outcome study of 168 patients undergoing corrective surgery for scoliosis, White et al. examined patient perceptions of function, pain, and appearance following surgical fusion and found that the white race was an independent predictor of self-perceived favorable outcomes as compared with the black race. ${ }^{34}$ Analogous to the aforementioned studies, our study demonstrated that AA patients had inferior baseline, 3-month, and 1-year postoperative PROs compared with those in white patients.

While a paucity of spine studies have identified the relationship between race and satisfaction, there are a few studies across various surgical specialties that have demonstrated a disparity. In a retrospective study of 90 patients who had undergone breast reconstructive surgery, Shaterian et al. identified race/ethnicity as an independent predictor of satisfaction. ${ }^{28}$ In a study of 989 patients who underwent total knee surgery, Jacobs et al. demonstrated that AA patients were 3 times more likely to be dissatisfied than white patients. ${ }^{15}$ Similarly, in a retrospective study of 3954 patients who had undergone resection for lung and colorectal cancer, Ejaz et al. identified race as being significantly associated with a lower likelihood of reporting an excellent quality of overall and surgical care. ${ }^{9}$ Interestingly, Cody et al. found that a nonwhite race was significantly associated with higher patient expectations among 352 patients undergoing foot and ankle surgery. ${ }^{8}$ Moreover, Mancuso et al. showed that poorer baseline patient-reported disability is associated with increased expectations of improvement after lumbar spine surgery. ${ }^{18}$ These studies parallel our findings that AA patients were associated with inferior satisfaction measures at 3 months and 1 year after elective lumbar surgery. Moreover, the differences in preoperative expectations may have implications for satisfaction with surgery. Racial disparities are integrated in various socioeconomic and educational levels; therefore, proper communication and understanding of the perception of health and the goals of surgery may normalize expectations and better overall satisfaction.

This study has several limitations that may impact interpretation of its findings. The variables were collected retrospectively and analyzed; therefore, this study is subject to the weaknesses of retrospective analysis, including reliance on the record keeping of others, difficulty in determining temporal relationships, and selection and information bias. The sample sizes of our cohorts are not similar and are therefore subject to bias when comparing complication, readmission, and postoperative variables, which may all affect PROs and patient satisfaction. Moreover, the impact that comorbidities, demographics, education, disability, and preexisting neuropathies have on postoperative course, PROs, and satisfaction measures cannot be ascertained and may have implications for the results. The chart review for this study involved just one institution and may not reflect areas with different patient populations. Given the variety of providers treating patients, the con- sistency of information and decision thresholds for surgical management is uncertain and may have implications for our results. Furthermore, the decision to operate was based on clinical presentation and radiographic evidence, which is subject to the provider's interpretation and may have implications for the results. Despite these limitations, this study has shown that racial disparities may play a role in short- and long-term PROs and patient satisfaction measures.

\section{Conclusions}

Our study suggests that there may be disparities in the perception of health, pain, and disability between AA and white patients at baseline and the short- and long-term follow-ups, which may influence overall patient satisfaction. Further studies are necessary to identify patient-specific factors associated with racial disparities that may be influencing outcomes to adequately measure and assess overall PROs and satisfaction after elective lumbar spine surgery.

\section{References}

1. Adogwa O, Elsamadicy AA, Mehta AI, Cheng J, Bagley CA, Karikari IO: Racial disparities in 30-day readmission rates after elective spine surgery: a single institutional experience. Spine (Phila Pa 1976) 41:1677-1682, 2016

2. Adogwa O, Elsamadicy AA, Mehta AI, Vasquez RA, Cheng J, Karikari IO, et al: Association between baseline affective disorders and 30-day readmission rates in patients undergoing elective spine surgery. World Neurosurg 94:432-436, 2016

3. Alosh H, Riley LH III, Skolasky RL: Insurance status, geography, race, and ethnicity as predictors of anterior cervical spine surgery rates and in-hospital mortality: an examination of United States trends from 1992 to 2005. Spine (Phila Pa 1976) 34:1956-1962, 2009

4. Arega A, Birkmeyer NJ, Lurie JD, Tosteson T, Gibson J, Taylor BA, et al: Racial variation in treatment preferences and willingness to randomize in the Spine Patient Outcomes Research Trial (SPORT). Spine (Phila Pa 1976) 31:2263-2269, 2006

5. Arnaoutakis DJ, Propper BW, Black JH III, Schneider EB, Lum YW, Freischlag JA, et al: Racial and ethnic disparities in the treatment of unruptured thoracoabdominal aortic aneurysms in the United States. J Surg Res 184:651-657, 2013

6. Black N: Patient reported outcome measures could help transform healthcare. BMJ 346:f167, 2013

7. Chibnall JT, Tait RC, Andresen EM, Hadler NM: Race differences in diagnosis and surgery for occupational low back injuries. Spine (Phila Pa 1976) 31:1272-1275, 2006

8. Cody EA, Mancuso CA, Burket JC, Marinescu A, MacMahon A, Ellis SJ: Patient factors associated with higher expectations from foot and ankle surgery. Foot Ankle Int 38:472-478, 2017

9. Ejaz A, Kim Y, Winner M, Page A, Tisnado D, Dy SE, et al: associations between patient perceptions of communication, cure, and other patient-related factors regarding patientreported quality of care following surgical resection of lung and colorectal cancer. J Gastrointest Surg 20:812-826, 2016

10. Elsamadicy AA, Adogwa O, Fialkoff J, Mehta AI, Vasquez RA, Cheng J, et al: Race as an independent predictor of temporal delay in time to diagnosis and treatment in patients with cervical stenosis: a study of 133 patients with anterior cervical discectomy and fusion. World Neurosurg 96:107110,2016 
11. Esnaola NF, Hall BL, Hosokawa PW, Ayanian JZ, Henderson WG, Khuri SF, et al: Race and surgical outcomes: it is not all black and white. Ann Surg 248:647-655, 2008

12. Firempong AO, Shaheen MA, Pan D, Drazin D: Racial and ethnic disparities in the incidence and mortality from septic shock and respiratory failure among elective neurosurgery patients. Neurol Res 36:857-865, 2014

13. Ford ES, Cooper RS: Racial/ethnic differences in health care utilization of cardiovascular procedures: a review of the evidence. Health Serv Res 30:237-252, 1995

14. Hughes K, Boyd C, Oyetunji T, Tran D, Chang D, Rose D, et al: Racial/ethnic disparities in revascularization for limb salvage: an analysis of the National Surgical Quality Improvement Program database. Vasc Endovascular Surg 48:402-405, 2014

15. Jacobs CA, Christensen CP, Karthikeyan T: Patient and intraoperative factors influencing satisfaction two to five years after primary total knee arthroplasty. J Arthroplasty 29:1576-1579, 2014

16. Kalanithi PS, Patil CG, Boakye M: National complication rates and disposition after posterior lumbar fusion for acquired spondylolisthesis. Spine (Phila Pa 1976) 34:19631969, 2009

17. Lad SP, Bagley JH, Kenney KT, Ugiliweneza B, Kong M, Bagley CA, et al: Racial disparities in outcomes of spinal surgery for lumbar stenosis. Spine (Phila Pa 1976) 38:927-935, 2013

18. Mancuso CA, Duculan R, Stal M, Girardi FP: Patients' expectations of lumbar spine surgery. Eur Spine J 24:23622369,2015

19. Martin J, Wang TY, Loriaux DB, Desai R, Adogwa O, Kuchibhatla M, et al: Race as a predictor of postoperative hospital readmission after spine surgery. Neurosurgery 63 (Suppl 1):191, 2016 (Abstract)

20. Martin JR, Wang TY, Loriaux D, Desai R, Kuchibhatla M, Karikari IO, et al: Race as a predictor of postoperative hospital readmission after spine surgery. J Clin Neurosci 46:21-25, 2017

21. McGirt MJ, Bydon M, Archer KR, Devin CJ, Chotai S, Parker SL, et al: An analysis from the Quality Outcomes Database, Part 1. Disability, quality of life, and pain outcomes following lumbar spine surgery: predicting likely individual patient outcomes for shared decision-making. J Neurosurg Spine 27:357-369, 2017

22. Quillin RC III, Wilson GC, Wima K, Hanseman DJ, Sutton JM, Shaw JJ, et al: Independent effect of black recipient race on short-term outcomes after liver transplantation. Surgery 157:774-784, 2015

23. Räsänen $P$, Ohman J, Sintonen H, Ryynänen OP, Koivisto AM, Blom M, et al: Cost-utility analysis of routine neurosurgical spinal surgery. J Neurosurg Spine 5:204-209, 2006

24. Schoenfeld AJ, Lurie JD, Zhao W, Bono CM: The effect of race on outcomes of surgical or nonsurgical treatment of patients in the Spine Patient Outcomes Research Trial (SPORT). Spine (Phila Pa 1976) 37:1505-1515, 2012

25. Schoenfeld AJ, Sieg RN, Li G, Bader JO, Belmont PJ Jr, Bono CM: Outcomes after spine surgery among racial/ethnic minorities: a meta-analysis of the literature. Spine J 11:381388, 2011

26. Schoenfeld AJ, Tipirneni R, Nelson JH, Carpenter JE, Iwashyna TJ: The influence of race and ethnicity on complications and mortality after orthopedic surgery: a systematic review of the literature. Med Care 52:842-851, 2014

27. Seicean A, Seicean S, Neuhauser D, Benzel EC, Weil RJ: The influence of race on short-term outcomes after laminectomy and/or fusion spine surgery. Spine (Phila Pa 1976) 42:3441, 2017

28. Shaterian A, Gandy J, Lalezari S, Smith S, Paydar K: Patient race and provider predict patient satisfaction following post-mastectomy breast reconstruction. World J Plast Surg 5:114-123, 2016

29. Singh JA, Lu X, Rosenthal GE, Ibrahim S, Cram P: Racial disparities in knee and hip total joint arthroplasty: an 18year analysis of national Medicare data. Ann Rheum Dis 73:2107-2115, 2014

30. Soroceanu A, Ching A, Abdu W, McGuire K: Relationship between preoperative expectations, satisfaction, and functional outcomes in patients undergoing lumbar and cervical spine surgery: a multicenter study. Spine (Phila Pa 1976) 37:E103-E108, 2012

31. Waljee J, McGlinn EP, Sears ED, Chung KC: Patient expectations and patient-reported outcomes in surgery: a systematic review. Surgery 155:799-808, 2014

32. Waljee JF, Ghaferi A, Cassidy R, Varban O, Finks J, Chung $\mathrm{KC}$, et al: Are patient-reported outcomes correlated with clinical outcomes after surgery?: A population-based study. Ann Surg 264:682-689, 2016

33. Wen T, Attenello FJ, He S, Cen Y, Kim-Tenser MA, Sanossian N, et al: Racial and socioeconomic disparities in incidence of hospital-acquired complications following cerebrovascular procedures. Neurosurgery 75:43-50, 2014

34. White SF, Asher MA, Lai SM, Burton DC: Patients' perceptions of overall function, pain, and appearance after primary posterior instrumentation and fusion for idiopathic scoliosis. Spine (Phila Pa 1976) 24:1693-1700, 1999

\section{Disclosures}

Dr. Karikari has been a consultant for NuVasive.

\section{Author Contributions}

Conception and design: all authors. Analysis and interpretation of data: Elsamadicy, Adogwa. Drafting the article: Elsamadicy, Kemeny, Sankey. Critically revising the article: all authors. Reviewed submitted version of manuscript: all authors. Approved the final version of the manuscript on behalf of all authors: Gottfried. Statistical analysis: Elsamadicy, Adogwa. Administrative/ technical/material support: Gottfried, Yarbrough, Lad, Karikari. Study supervision: Gottfried, Goodwin, Yarbrough, Lad, Karikari.

\section{Correspondence}

Oren N. Gottfried: Duke University Medical Center, Durham, NC. oren.gottfried@duke.edu. 